Advances in Radiation Biology

Vol. 1. Edited by Leroy G. Augenstein, R. Mason and H. Quastler. Pp. $\mathrm{x}+285$. (New York and London: Academic Press, 1964.) 888.

$A^{D V A N C E S}$ in Radiation Biology cannot be recommended as light holiday reading. The editors say "the need is clear for a series of review articlos designed to keop more of us in contact with branches of the subject other than our own", but there is a danger that what they offer will have the opposite effect, of convincing the average radiation biologist that he has no hope of grasping the physico-chemical fundamentals of his subject and of driving him to seek a soft option in some corner where such knowledge is unnecessary. For the brave, however, and none but the brave, this book is just right, though the title is an over-simplification and it should be called "Advances in Radio-bio-physico-chemistry".

It starts with a comparatively easy and clear account of the radiolysis products of water, with valuable tables of rate constants for reactions of the electron, the hydrogen atom and the hydroxyl radical, which should help to keep speculators on the rails; but even in this first chapter it foreshadows the horrors that are to come by saying, "a knowledge of rate constants . . . is only a small part of the problem. The reaction of a radical with a molecule produces a second radical. The nature of the new radical is not even known for most of the reactions given in Tables I, II and III'. This prepares us, somewhat inadequately, for shocks such as the table on p. 180 showing the nineteen irradiation products of such an unreactive substance as $\alpha$-aminobutyric acid.

The second chapter, on photosynthesis, though excellent, should not be included unless the title is further expanded to "Radio- and Photo- ... etc.", because the irrational but useful convention is fully established that 'radio-' refers to 'ionizing' radiation and 'photo-' to visible light. Nevertheless, biologists who wish to get a glimmering of applied quantum mechanics, beautifully expounded, would do well to read it. After this it is restful to read that tritium has an atomic weight of three and to meet the nice compact table on pp. 110-112 summarizing the depressed growth and suicide that it causes in all sorts of biological material. The next chapter goes to the heart of the radiobiological problem, collecting all those puzzling cases where effects are produced by far smaller doses of radiation then can possibly be explained. The next chapter, on amino-acids, will break the back of all but the toughost reader, not with high-brow physics, but with its mass of empirical chemistry. The final chapter uses all the previously enunciated concepts to discuss the inactivation of enzymes, after which the reader goes on holiday with some nice non-controversial light reading such as Boilstein. J. ST. L. PHiLPot

\section{The Systematic Identification of Organic Compounds}

A Laboratory Manual. Fifth edition. By R. I. Shriner. R. C. Fuson and D. Y. Curtin. Pp. ix +458 . (New York, London and Sydney: John Wiley and Sons, Inc., 1964.) $59 s$.

THE fifth edition of this well-known publication on the qualitative analysis of organic compounds will continue to be warmly welcomed by the student and research worker as a supreme laboratory vade-mecum.

The fundamental chemical and physical tests leading to the identification of organic compounds are lucidly described. Much attention is directed to the manner in which laboratory reports on unknown substances should be represented and there aro a number of most useful examples of the final sequential system of deductive reasoning which leads to the positive identification of the unknown compound.

Excellent chapters are provided on instrumental applications, the methods of infra-red and ultra-violet spectroscopy being succinctly demonstrated. Nuclear magnetic resonance phenomena are concisely explained with most adequate references to more advanced textbooks.

The book concludes with nearly a hundred pages of physico-chemical data associated with derivatives of hydrocarbons, amines, nitrilos, etc.; a most valuable compilation, providing confirmatory evidence of identification of unequivocal character. The "Sets" of problems for students which the authors have provided must prove a most valuable educational aid. Like its predecessors, this is a first-class book for teachers and students in schools, technical colleges and universities.

\section{T. LewIS}

\section{Proceedings of the International Symposium on Chemo- therapy of Cancer}

Lugano, 28th April to 1st May, 1964. Edited by Prof. Placidus A. Plattner. Pp. ix + 324. (Amsterdam, London and New York: Elsevier Publishing Company, 1964.) $75 s$

IN the Procedings of the International Symposium on the Chemotherapy of Cancer, organized by the Swiss Academy of Medical Seiences, the editorial hand of Prof. P. A. Plattner has rested lightly on his expert contributors. This results in a volume in which the individual styles of the authors are retained, as is the sense of occasion, so that, provided the reader approaches the book in the spirit in which it has been compiled, he is carried easily through it.

The subject of the symposium is well and authoritatively covered. There are chapters on the biochemistry and modes of action of alkylating agents and antimetabolites, on clinical experience with established drugs, laboratory and clinical reports on a number of newer ones, and a section entitled (perhaps unhappily) "Selective Toxicity of Anti-Tumor Compounds", in which the toxic effects due to non-specificity of action are clearly and frankly set out. It is hoped that the decision of the organizers to include in this symposium a paper on polyoma virus and its oncogenic action will not result in an interesting review article being missed by some who would profit from it.

This, elearly, is a book to be read by all those engaged with problems of the treatment of cancer, whether in the laboratory or in the ward. It is also to be commended to workers in the basic sciences who, by reading what is written, noting what is not, and examining critically each assumption (both stated and implied) made throughout the book, may well find pointers to help them to provide the fundamental information on which a rational and successful therapy may be based. D. C. RoBerts

Elements of the Natural Movement of Population By Egon Vielrose. Translated from the Polish by J. Dobosz. Translation edited by $\mathrm{H}$. Infeld and P. F. Knightsfield. Pp. 288. (London and New York : Pergamon Press; Warszawa: Panstwowe Wydawnictwo Ekonomiczne, 1965.) 70s. net.

FLEMENTS of the Natural Movement of Population is neither an introduction to demographic analysis nor an outline of the development of world population nor an attempt to explain differential rates of growth. It consists of an extensive commentary on selected vital statistics, dealing with population structure, fertility, nuptiality and mortality. It is largely derivative and little attempt is made to take account of post-war advances in demography. Moreover, the vital statistics discussed are used rather uncritically and with little attempt to assess the adequacy of the system by which they are collected. To give but one random example, on p. 146 the average numbers of live births per female in Angola and Australia are given side by side without any indication of the relative reliability of the data.
E. GREBENIK 